\title{
Meningitis as an Initial Presentation of COVID-19: A Case Report
}

\author{
Sidra Naz ${ }^{1 \dagger}$, Muhammad Hanif ${ }^{2 \star \dagger}$, Muhammad Adnan Haider ${ }^{3 \dagger}$, Mukarram Jamat Ali ${ }^{4 \dagger}$, \\ Muhammad Umer Ahmed ${ }^{5 \dagger}$ and Sana Saleem ${ }^{1+}$ \\ ${ }^{1}$ Department of Internal Medicine, University of Health Sciences, Lahore, Pakistan, ${ }^{2}$ Khyber Medical College Peshawar, \\ Hayatabad Medical Complex, Peshawar, Pakistan, ${ }^{3}$ Department of Internal Medicine, Allama Iqbal Medical College, Lahore, \\ Pakistan, ${ }^{4}$ Department of Internal Medicine, King Edward Medical University Lahore, Lahore, Pakistan, ${ }^{5}$ Ziauddin University \\ and Hospital, Ziauddin Medical College, Karachi, Pakistan
}

The common presenting symptoms of fever, fatigue, and mild respiratory symptoms like dry cough, are associated with COVID-19, however, patients can also develop neurological manifestations like headache, anosmia, hyposmia, dysgeusia, meningitis, encephalitis, and acute cerebrovascular accidents during the disease. Although very rare, these neurological manifestations are sometimes the sole initial presenting complaint of COVID-19. This case report discusses patients where the initial presenting symptoms seemed to be exclusive to meningitis but the later diagnosis was COVID-19. It is important to increase awareness of these rare presentations in physicians and healthcare workers and facilitate early diagnosis and management to prevent the horizontal spread of the disease.

Keywords: SARS-CoV-2, COVID-19, meningitis, meningo encephalitis, neurological manifestation

\section{INTRODUCTION}

Following its emergence in Wuhan, China in December 2019, the Coronavirus disease 2019 (COVID-19), which is caused by severe acute respiratory coronavirus-2 (SARS-CoV-2), has become a pandemic (1) and been declared a global health emergency (2). In addition to the common presenting symptoms of fever, fatigue, and mild respiratory symptoms like dry cough, patients with COVID-19 can also develop neurological manifestations like headache, anosmia, hyposmia, dysgeusia, meningitis, encephalitis, and acute cerebrovascular accidents during the course of the disease $(3,4)$. The first case of meningitis associated with COVID-19 was reported in Japan in February 2020 (5). Since then, two or three more cases of meningoencephalitis have also been reported in the United States (6-8). Although very rare, these neurological manifestations sometimes are the sole initial presenting complaint of COVID-19. In this article, we present a case discussion of instances in which the initial presenting symptoms were exclusive to meningitis and later diagnosed as COVID-19, to make physicians and healthcare workers cognizant of such rare presentations. It is important to diagnose and manage these patients at the earliest possible stage of treatment to prevent the horizontal spread of COVID-19.

\section{CASE REPORT}

A 21-years-old male medical student with no known co-morbidities was presented to an emergency department with a 2-days history of frontal headache and fever, and 1-day history of neck stiffness. He denied any cough, shortness of breath, body aches, and diarrhea (Table 1). On physical 
TABLE 1 | Demographics and clinical characteristics.

\begin{tabular}{ll}
\hline Characteristics & Patient \\
\hline Age & 21 \\
Sex & Male \\
Significant past medical history & None \\
Symptoms onset & Frontal headache, Fever, and neck stiffness \\
Respiratory distress & Developed 5 days after symptoms onset \\
Cause of death & Multi-organ failure \\
\hline
\end{tabular}

TABLE 2 | Cerebrospinal fluid analysis.

\begin{tabular}{ll}
\hline Tests & Results \\
\hline Appearance & Clear with no xanthochromia \\
Lactate dehydrogenase & $48 \mathrm{U} / \mathrm{L}$ \\
Glucose & $83 \mathrm{mg} / \mathrm{dL}$ \\
Protein & $164 \mathrm{mg} / \mathrm{dL}$ \\
RBCs & 05 \\
Neutrophils & 10 \\
Lymphocytes & 90 \\
Gram stain/Ziehl-Neelsen Stain & No micro-organisms seen \\
HSV-PCR & Negative \\
VZV-PCR & Negative \\
Culture & No growth after 48h of incubation \\
\hline
\end{tabular}

examination, he was alert, oriented, and awake with a Glasgow coma scale score of 15/15. He had a fever of $101 \mathrm{~F}$ and neck rigidity with absent Babinski sign and $2+$ deep tendon reflexes.

Based on clinical presentations and initial blood work up, bacterial meningitis was suspected and he was started on intravenous antibiotics empirically after cerebral spinal fluid (CSF) was sent for analysis. CSF analysis showed a picture of viral meningitis and in addition to empiric antibiotics, he was also given antiviral agents. CSF gram staining, Ziehl-Neelsen staining, and culture showed no microorganisms, and tests for Herpes simplex type 1, Herpes simplex type 2, and Varicella zoster virus were negative (Table 2 ).

On day 2 of hospitalization (day 4 of initial symptoms), he had swelling of his left eye, and a computed tomography (CT) head was ordered on neurologist recommendation which showed no significant findings. Even though he had no respiratory symptoms of cough and shortness of breath, a chest x-ray was ordered due to the ongoing COVID-19 pandemic and it showed a patch of consolidation. Based on these X-ray findings, testing for COVID-19 was done and a reverse transcriptase polymerase chain reaction for SARS-CoV-2 on nasopharyngeal swab was positive on day 5 of hospitalization. On that same day, he developed tachycardia, tachypnea, and hypotension; his oxygen saturation started to drop progressively and was put on a ventilator. His chest X-ray showed diffuse multi-lobar infiltrates consistent with acute respiratory distress syndrome (Figure 1). His laboratory work up showed respiratory acidosis and a picture of disseminated intravascular coagulation (DIC) (Table 3). One day later, he passed away due to multi-organ failure.

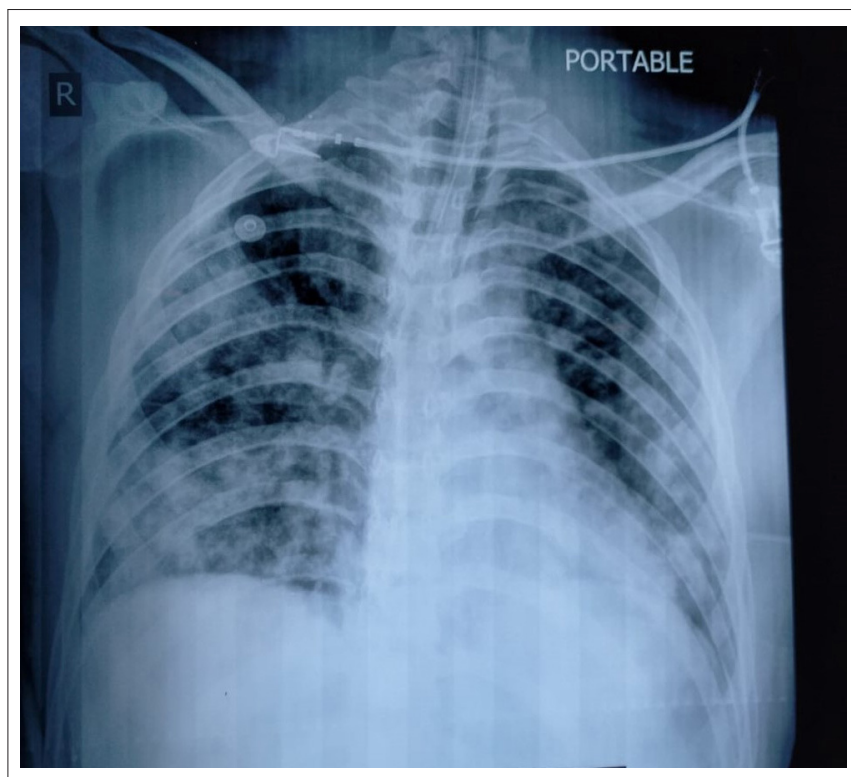

FIGURE 1 | Chest X-ray shows diffuse multi-lobar infiltrates consistent with acute respiratory distress syndrome.

TABLE 3 | Laboratory findings (on day 5 of initial symptoms).

\begin{tabular}{|c|c|}
\hline Test & Results \\
\hline Leukocytes count & $2.2\left(\times 10^{9} / \mathrm{I}\right)$ \\
\hline Lymphoctes & $07 \%$ \\
\hline Neutrophils & $89 \%$ \\
\hline Platelet count & $65\left(\times 10^{9} / 1\right)$ \\
\hline Serum procalcitonin & 50 ng/mL \\
\hline Serum ferritin & $1,358 \mathrm{ng} / \mathrm{mL}$ \\
\hline Serum CRP & $>32 \mathrm{mg} / \mathrm{dL}$ \\
\hline Serum LDH & $527 \mathrm{U} / \mathrm{L}$ \\
\hline Serum CK-MB & 54 U/L \\
\hline Albumin/globulin ratio & 0.8 \\
\hline Serum AST & $88 \mathrm{U} / \mathrm{L}$ \\
\hline Serum albumin & $2.6 \mathrm{~g} / \mathrm{dL}$ \\
\hline Serum total protein & $5.7 \mathrm{~g} / \mathrm{dL}$ \\
\hline International normalized ratio & 1.7 \\
\hline Protheombin time & $18 \mathrm{~s}$ \\
\hline Plasma FDPs & 8,340 ng/FEUm \\
\hline $\mathrm{pH}$ & 7.295 \\
\hline $\mathrm{HCO}_{3}$ & $22.3 \mathrm{mmol} / \mathrm{L}$ \\
\hline $\mathrm{PCO}_{2}$ & $52 \mathrm{mmHg}$ \\
\hline Base excess/deficit & $-2.7 \mathrm{mmol} / \mathrm{L}$ \\
\hline
\end{tabular}

\section{DISCUSSION}

This case indicates that in addition to common presenting symptoms of fever, fatigue, and mild respiratory symptoms like dry cough and shortness of breath, patients with COVID19 can also develop neurological manifestations like headache, anosmia, hyposmia, dysgeusia, meningitis, encephalitis, and 
acute cerebrovascular accidents during the course of the disease (3), which highlights the neurotropic potential of SARS-CoV2 (4). To date, the underlying pathophysiological mechanisms through which SARS-CoV-2 implicates the central nervous system (CNS) are not fully understood, however, the following mechanism have been proposed in other studies $(9,10)$ :

1. Direct spread of SARS-CoV-2 to brain.

2. Spread through neuronal pathways.

3. Haematogenous spread to brain.

4. Immune mediated injury (cytokine storm syndrome).

5. Hypoxic related injury to CNS.

In this case, the patient initially presented with fever and frontal headache along with neck stiffness. There was a delay in the diagnosis because this initial presentation of patients with COVID-19 is rare and only a few cases have been reported so far. To the best of our knowledge, in the USA only two cases have been reported where the initial presenting complaint was a meningitis-like illness $(6,8)$.

The RBCs in the CSF are an indication of blood brain barrier breach which can occur in SARS-CoV-2 and has been linked to cytokine storm syndrome. Cytokine storm syndrome related damage to the central nervous system has also been implicated in many other viral infections (11). However, only five RBCs in the CSF of our patient could be attributed to traumatic lumbar puncture. Likewise, it has also been suggested that cytokine storm syndrome causes severe symptoms and brain damage in patients with COVID-19 and this is supported by the fact that patients having severe symptoms associated with SARS-CoV-2 infection respond to interleukin-6 (IL-6) receptor blocker [i.e., tocilizumab (12)]. Together with typical picture of viral meningitis on CSF analysis, negative polymerase chain reaction for herpes simplex, and positive reverse transcriptase polymerase chain reaction for

\section{REFERENCES}

1. Lu H, Stratton CW, Tang YW. Outbreak of pneumonia of unknown etiology in Wuhan, China: the mystery and the miracle. J Med Virol. (2020) 92:4012. doi: 10.1002/jmv. 25678

2. Wang C, Horby PW, Hayden FG, Gao GF. A novel coronavirus outbreak of global health concern. Lancet. (2020) 395:470-3. doi: 10.1016/S0140-6736(20) 30185-9

3. Mao L, Jin $\mathrm{H}$, Wang $\mathrm{M}$, Hu $\mathrm{Y}$, Chen $\mathrm{S}$, $\mathrm{He} \mathrm{Q}$, et al. Neurologic manifestations of hospitalized patients with coronavirus disease 2019 in Wuhan, China. JAMA Neurol. (2020) 77:1-9. doi: 10.1001/jamaneurol.20 20.1127

4. Ahmed MU, Hanif M, Ali MJ, Haider MA, Kherani D, Memon GM, et al. Neurological manifestations of COVID-19 (SARS-CoV2): a review. Front Neurol. (2020) 11:518. doi: 10.3389/fneur.2020. 00518

5. Moriguchi T, Harii N, Goto J, Harada D, Sugawara H, Takamino J, et al. A first case of meningitis/encephalitis associated with SARSCoronavirus-2. Int J Infect Dis. (2020) 94:55-8. doi: 10.1016/j.ijid.2020. 03.062

6. Duong L, Xu P, Liu A. Meningoencephalitis without respiratory failure in a young female patient with COVID-19 infection in Downtown Los Angeles, early April 2020. Brain Behav Immun. (2020) 87:83. doi: 10.1016/j.bbi.2020. 04.024
SARS-CoV-2 on a nasopharyngeal swab, we labeled this case of meningitis as viral meningitis secondary to SARS-CoV-2. Although there have been some cases reported of SARS-CoV2 detection in CSF by reverse transcriptase polymerase chain reaction (RT-PCR) $(5,13)$, yet US Food and Drug Administration has not approved any test to detect SARS-CoV-2 in CSF. Additionally, as the CT head was normal in this case, we should have ordered a magnetic resonance imaging of the brain for detailed imaging.

During this ongoing pandemic, there is a need to make physicians and other healthcare workers cognizant of rare presentations such as this, so that we can diagnose and manage these patients at the earliest possible opportunity, which prevents the horizontal spread of the virus and ensures patient safety. We recommend testing of CSF for SARS-CoV-2 via RT-PCR in suspected cases.

\section{DATA AVAILABILITY STATEMENT}

The raw data supporting the conclusions of this article will be made available by the authors, without undue reservation.

\section{ETHICS STATEMENT}

Written informed consent was obtained from the individual(s) for the publication of any potentially identifiable images or data included in this article.

\section{AUTHOR CONTRIBUTIONS}

All authors listed have made a substantial, direct and intellectual contribution to the work, and approved it for publication.

7. Poyiadji N, Shahin G, Noujaim D, Stone M, Patel S, Griffith B. COVID19-associated acute hemorrhagic necrotizing encephalopathy: CT and MRI features. Radiology. (2020) 296:201187. doi: 10.1148/radiol.20202 01187

8. Packwood R, Galletta G, Tennyson J. An unusual case report of COVID-19 presenting with meningitis symptoms and shingles. Clin Practice Cases Emergency Med. (2020) 4:316-20. doi: 10.5811/cpcem.2020.4. 47557

9. Zhao Y, Zhao Z, Wang Y, et al. Single-cell RNA expression profiling of ACE2, the putative receptor of Wuhan 2019-nCov. bioRxiv. (2020). doi: 10.1101/2020.01.26.9 19985

10. Baig AM, Khaleeq A, Ali U, Syeda $H$. Evidence of the COVID-19 virus targeting the CNS: tissue distribution, hostvirus interaction, and proposed neurotropic mechanisms. ACS Chem. Neurosci. 11:995-8. doi: 10.1021/acschemneuro.0c 00122

11. Popescu CP, Florescu SA, Lupulescu E, Zaharia M, Tardei G, Lazar M, et al. Neurologic complications of influenza B virus infection in adults, Romania. Emerg Infect Dis. (2017) 23:574-81. doi: 10.3201/eid2304.161317

12. Zhang $\mathrm{C}, \mathrm{Wu} \mathrm{Z}, \mathrm{Li}$ JW, Zhao H, Wang GQ. Cytokine release syndrome in severe COVID-19: interleukin-6 receptor antagonist tocilizumab may be the key to reduce mortality. Int J Antimicrob Agents. (2020) 55:105954. doi: 10.1016/j.ijantimicag.2020.105954 
13. Huang YH, Jiang D, Huang JT. SARS-CoV-2 detected in cerebrospinal fluid by PCR in a case of COVID-19 encephalitis. Brain Behav Immun. (2020) 87:149. doi: $10.1016 /$ j.bbi.2020.05.012

Conflict of Interest: The authors declare that the research was conducted in the absence of any commercial or financial relationships that could be construed as a potential conflict of interest.
Copyright $\odot 2020 \mathrm{Naz}$, Hanif, Haider, Ali, Ahmed and Saleem. This is an open-access article distributed under the terms of the Creative Commons Attribution License (CC $B Y)$. The use, distribution or reproduction in other forums is permitted, provided the original author(s) and the copyright owner(s) are credited and that the original publication in this journal is cited, in accordance with accepted academic practice. No use, distribution or reproduction is permitted which does not comply with these terms. 